\title{
Low-glucose medium induces ORP150 expression and exerts inhibitory effect on apoptosis and senescence of human breast MCF7 cells
}

\author{
Rafał Krętowski, Anna Stypułkowska and Marzanna Cechowska-Pasko ${ }^{凶}$ \\ Department of Pharmaceutical Biochemistry, Medical University of Bialystok, Bialystok, Poland
}

\begin{abstract}
Glucose deprivation is a factor evoking endoplasmic reticulum (ER) stress and induction of expression of an oxygen-regulated protein of $150 \mathrm{kDa}$ (ORP150). We studied the effect of inducible overexpression of ORP150 on senescence and apoptosis of human breast carcinoma cells (MCF7) and human skin fibroblasts. We found an inhibitory effect of ORP150 on apoptosis and senescence of MCF7 cells, but not fibroblasts in ER stress conditions. An increased expression of senescence-associated $\beta$-galactosidase and acid $\beta$-galactosidase activity (biomarkers of cellular senescence) was observed. We suggest that ORP150 induction in cancer cells can promote tumour progression and may be a major cause of their resistance to chemotherapeutics.
\end{abstract}

Key words: apoptosis; $\beta$-galactosidase; ORP150; senescence

Received: 10 December, 2012; revised: 29 April, 2013; accepted: 05 June, 2013; available on-line: 12 June, 2013

\section{INTRODUCTION}

Oxygen-regulated protein of molecular mass 150 $\mathrm{kDa}$ (ORP150) and glucose-regulated protein of molecular mass 170 (GRP170) are endoplasmic reticulum (ER) chaperones that facilitate protein folding (Yoshida, 2007). GRP170 is a glycosylated form of ORP150. The ORP150/GRP170 system is part of the ER machinery that assists in the folding and assembly of secretory and membrane proteins within the ER (Flores-Diaz et al., 2004). The expression of ORP150 increases in a range of pathologic situations such as brain ischaemia (Matsushita et al., 1998), atherosclerotic plaques (Tsukamoto et al., 1996) and malignant tumours (Tsukamoto et al., 1998), suggesting that this chaperone is a factor in the cellular response to environmental stress.

Numerous stress conditions, such as glucose or oxygen deprivation, slow down protein folding and cause accumulation of unfolded/misfolded proteins in the cell (Ma \& Hendershot, 2001; Harding et al., 2002; Kaufman et al., 2002). The accumulation of unfolded proteins activates so called "unfolded protein response" (UPR), which involves at least four types of responses: translation attenuation (phosphorylation of translation initiation factor 2); increased folding capacity (biosynthesis of chaperones); enhanced degradation of misfolded proteins (endoplasmic-reticulum-associated protein degradation pathway); and apoptosis (when the stress is severe and unsolvable) (Ma \& Hendershot, 2001; Harding et al., 2002; Kaufman et al., 2002).

Apoptosis plays a major role in the control of cancer development. In fact, cells encounter multiple apoptotic stimuli during cancer progression, including nutrient deprivation or hypoxia. Accordingly, it has been suggested that the well-documented anti-apoptotic potential of chaperones may play a critical role in the suppression of apoptosis in cancer cells (Jolly \& Morimoto, 2000; Soti et al., 2003; Mosser \& Morimoto; 2004). Recently, attention has shifted towards a novel role of cell senescence in the control of cancer development, and with this shift our view on the role of chaperones in cancer has also evolved towards appreciation of their major role in the regulation of senescence (Sherman \& Multhoff, 2007).

Senescence can be generally characterised as a cellular stress response. It is a signal transduction process that leads to an irreversible growth arrest of cells in the G1 cell cycle phase (Saretzki, 2010). Our knowledge about cell senescence occurring in vivo and, most importantly, as a desired outcome of cancer treatment, is very limited and can still be viewed as an emerging field of study. The term senescence was originally applied to the irreversible growth arrest of cells after prolonged proliferation under in vitro cell culture conditions. Now it has been extended to the irreversible proliferation arrest of cells caused by various stresses, including oxidative damage, telomere dysfunction, DNA damage, and oncogeneinduced senescence as well (Chang et al., 1999a; b; Roninson, 2003; Dimri, 2005; Collado, 2007; Palaniyappan, 2009). Tumour cells are exposed to many different, external as well as internal sources of stress, therefore the induction of senescence constitutes an important block to tumour progression (Saretzki, 2010). Senescence is a potent anti-carcinogenic program and the process of neoplastic transformation involves a series of events that allow cells to bypass senescence by inactivation of senescence associated pathways. Still, many tumour cells have retained the capacity to senesce in response to external stress stimuli. Most conventional anti-cancer therapies activate DNA damage signaling pathways, thus aiming to induce primarily apoptotic cell death, but often the treated cells do not die by apoptosis but rather undergo growth arrest or senescence. It is not fully understood currently which specific signals cause cells to undergo either senescence or initiate apoptosis (Saretzki, 2010).

An increase of lysosomal mass is characteristic for senescent cells leading to higher expression of the lysosomal enzyme acid $\beta$-D-galactosidase (EC 3.2.1.23) (Nishi-

e-mail: mapasko@gmail.com

Abbreviations: AIF, apoptosis inducing factor; ECM, extracellular matrix; ER, endoplasmic reticulum; FBS, fetal bovine serum; FITC, fluorescein isothiocyanate; GRP170, glucose-regulated protein 170; HER-2, human epidermal growth factor receptor 2 oncogene; HSP70, heat shock protein 70; ORP150, oxygen-regulated protein 150; PI, propidium iodide; PTEN, phosphatase and tensin homolog deleted on chromosome ten; $R A F$, serine/threonine-protein kinase proto-oncogene; SIPS, stress-induced premature senescence; TBS, tris-buffered saline; UPR, unfolded protein response. 
gaki \& Okada, 1998). It cleaves $\beta$-linked terminal galactosyl residues from a wide range of naturally occurring substrates, such as gangliosides, glycoproteins and glycosaminoglycans, as well as a number of artificial substrates (Kurz et al., 2000; Noppe et al., 2009). Furthermore, the cytochemically detectable senescence-associated $\beta$-galactosidase (SA- $\beta$-galactosidase) is widely used as a marker of cellular senescence in vitro and in vivo (Lundberg et al., 2000; Severino et al., 2000; Yi, 2009). Kurz et al. (Kurz et al., 2000) demonstrated a strong relationship between senescence and the increase in cellular lysosomal mass, $\beta$-galactosidase protein mass, $\beta$-galactosidase activity under various intracellular $\mathrm{pH}$ conditions, and SA- $\beta$-galactosidase cytochemical staining.

Senescence parallels an accumulation of damaged proteins in the cell. The attenuation of molecular chaperone inducibility and the simultaneous accumulation of damaged proteins raises the possibility that preservation of protein homeostasis is a major determinant of the occurrence and duration of cellular senescence (Soti et al., 2003).

The role of oxygen regulated proteins (ORP150) in cancerogenesis and senescence remains unclear. We investigated the effect of ORP150 induction, in ER stress conditions, on the activity of senescence markers; SA- $\beta$ galactosidase and acid $\beta$-D-galactosidase in MCF7 cells in comparison to normal fibroblasts, and correlation of these activities with apoptosis of these cells.

\section{MATERIALS AND METHODS}

Reagents. Cell-culture media [high-glucose DMEM (4.5 mg/ml, $25 \mathrm{mM}$ ) and low-glucose DMEM (0.5 mg/ $\mathrm{ml}, 2.8 \mathrm{mM})$ ], glutamine, penicillin, streptomycin, trypsinEDTA were provided by Invitrogen (San Diego, USA), passive lysis buffer by Promega (Madison, USA), FBS Gold by Gibco (San Diego, USA), BCA Protein Assay Kit by Thermo Scientific (Rockford, USA), PE Annexin $\mathrm{V}$ Apoptosis Detection Kit I by BD Pharmingen ${ }^{\mathrm{TM}}$ (CA, USA), Senescence Detection Kit by bioVision (CA, USA), p-nitrophenyl $\beta$-D-galactopyranoside, Sigma-Fast $\mathrm{BCIP} / \mathrm{NBT}$ reagent by Sigma (St Louis, MO, USA), monoclonal (mouse) anti-human ORP150 antibody by IBL (Gunma, Japan) and alkaline phosphatase-labelled anti-mouse immunoglobulin $G$ by Rockland (Pennsylvania, USA)

Cell cultures. Human breast cancer cell line MCF7 (HTB-22) and normal human skin fibroblast cell line (CRL1474) were obtained from American Type Culture Collection (ATCC). Cells were maintained in Dulbecco's modified Eagle's medium (DMEM) containing glucose at $4.5 \mathrm{mg} / \mathrm{ml}$ (high-glucose DMEM) supplemented with $10 \%$ heat-inactivated foetal bovine serum GOLD (FBS GOLD), $2 \mathrm{mM}$ L-glutamine, penicillin $(100 \mathrm{U} / \mathrm{ml})$ and streptomycin $(100 \mu \mathrm{g} / \mathrm{ml})$. Cells were cultured in Falcon flasks (BD) in a $5 \% \mathrm{CO}_{2}$ incubator (Galaxy $\mathrm{S}+$ ), at $37^{\circ} \mathrm{C}$. Subconfluent cultures were detached with $0.05 \%$ trypsin, $0.02 \%$ EDTA in calcium-free phosphate-buffered saline and counted in a Scepter cell counter (Millipore), then $5 \times 10^{5}$ cells were seeded in six-well plates in $2 \mathrm{ml}$ of growth medium for determination of acid $\beta$-D-galactosidase activity and protein concentration. For cytochemical detection of SA- $\beta$-galactosidase the cells were seeded on Petri dishes $\left(9.5 \mathrm{~cm}^{2}\right)$ and incubated for 3 days in the high-glucose DMEM. In these conditions they reached $70-80 \%$ confluenc. After this time the medium was removed and replaced with $2 \mathrm{ml}$ of a fresh DMEM, high- or low-glucose, supplemented with $2 \mathrm{mM}$
L-glutamine, penicillin $(100 \mathrm{U} / \mathrm{ml})$ and streptomycin $(100 \mu \mathrm{g} / \mathrm{ml})$. The incubation was continued for 12,24 or 48 hours. No increase in cell density was observed in that period. After incubation the culture media were removed, the cells were washed with PBS and submitted to the action of lysis buffer for determination of acid $\beta$-D-galactosidase and protein assay. It allowed the detachment of the cells and extracellular matrix from the bottom of culture vessels and their suspension in the buffer. The cells incubated on Petri dishes were used for cytochemical detection of SA- $\beta$-galactosidase.

Detection of SA- $\beta$-galactosidase. Cells were incubated in high- or low-glucose DMEM. The incubation was continued for 12,24 or $48 \mathrm{~h}$. After this time the medium was removed and the cells were washed with $2 \mathrm{ml}$ of PBS. SA- $\beta$-galactosidase-positive cells were detected using Senescence Detection Kit (bioVision). Briefly, the cells were fixed with $1 \mathrm{ml}$ of Fixative Solution for 15 minutes at room temperature and washed with $2 \mathrm{ml}$ of PBS. After washing Staining Solutions Mix was added [940 $\mu$ l of Staining Solution, $10 \mu \mathrm{l}$ of Staining Supplement and $10 \mu \mathrm{l}$ of 5 -bromo4-chloro-3-indolyl- $\beta$-D-galactopyranoside (X-gal) at 20 $\mathrm{mg} / \mathrm{ml}$ concentration] at $\mathrm{pH} 6.0$, which $\mathrm{pH}$ ensures that nonsenescent cells remain unstained. The cells were incubated for $12 \mathrm{~h}$ at $37^{\circ} \mathrm{C}$, washed with PBS and photographed.

Determination of acid $\beta$-D-galactosidase activity. The activity of acid $\beta$-D-galactosidase was determined colorimetrically by the method of Chatterjee et al. (1975). Briefly, $40 \mu \mathrm{l}$ of $0.1 \mathrm{M}$ phosphate-citrate buffer $(\mathrm{pH} 4.3)$ and $30 \mu \mathrm{l}$ of $20 \mathrm{mM}$ solution of $\mathrm{p}$-nitrophenyl $\beta$-D-galactopyranoside were added to $10 \mu \mathrm{l}$ of cell lysate. The samples were incubated at $37^{\circ} \mathrm{C}$ for 60 minutes. The enzymatic reaction was terminated by adding $200 \mu \mathrm{l}$ of $0.2 \mathrm{M}$ borate buffer ( $\mathrm{pH}$ 9.8). The released p-nitrophenol was measured colorimetrically using an Infinite M200 microplate reader (Tecan, Austria) and computer program Magellan 6 (Tecan, Austria). Absorbance was measured in duplicate, at wavelength $\lambda=405 \mathrm{~nm}$. The enzyme activity was expressed as picokatal per $\mathrm{mg}$ of protein (pkat/mg).

Detection of apoptosis and necrosis. Apoptosis and necrosis was evaluated by flow cytometry on FACSCanto II cytometer (Becton Dickinson). The cells were trypsinised, resuspended in DMEM and then in binding buffer. Cells were stained with FITC Annexin V and PI for $15 \mathrm{~min}$ at room temperature in the dark following the manufacturer's instructions (FITC Annnexin $\mathrm{V}$ apoptosis detection Kit I). Data were analysed with FACSDiva software and dead cells were excluded based on forward- and side-scatter parameters.

Sodium dodecyl sulphate/Polyacrylamide gel electrophoresis (SDS/PAGE). Cells were washed with cold PBS and solubilised in $200 \mu \mathrm{l}$ of passive lysis buffer per well. The lysates were centrifuged for $10 \mathrm{~min}$, at $10000 \times \mathrm{g}$, at $4^{\circ} \mathrm{C}$. Samples of lysates containing $30 \mu \mathrm{g}$ of protein were subjected to SDS/ PAGE, as described by Laemmli (1970). The following Bio-Rad unstained standards were used: myosin $(200 \mathrm{kDa})$, galactosidase (116.2 kDa), phosphorylase b $(97.4 \mathrm{kDa})$, bovine serum albumin $(66.2 \mathrm{kDa})$, ovalbumin $(45 \mathrm{kDa})$. The electrophoresis was run for $40-45$ minutes. In each experiment $7.5 \%$ polyacrylamide gel and constant current $(25 \mathrm{~mA})$ were used.

Immunoblotting. The proteins were transferred to nitrocellulose membranes and then pre-treated for 2 hours with Tris/buffered saline (TBS) containing 0.05\% Tween 20 (TBS-T) and 5\% non-fat dry milk, at room 
temperature. Membranes were probed for $16 \mathrm{~h}$ with a mixture containing anti-ORP150 antibody $(1: 1000)$ in $5 \%$ dry milk in TBS-T, at $4^{\circ} \mathrm{C}$. Then the alkaline phosphatase-conjugated antibody against mouse $\operatorname{IgG}$ (whole molecule) at a 1:7500 dilution was added for $1 \mathrm{~h}$ in TBS$\mathrm{T}$ with slow shaking. The membrane was washed with TBS-T (five times for $5 \mathrm{~min}$ ) and exposed to Sigma-Fast BCIP/NBT reagent.

Protein assay. Protein concentration in cell lysates was determined by the method of Smith et al. (1985) using BCA Protein Assay Kit (Thermo Scientific, USA). Bovine serum albumin was used as a standard.

Statistical analysis. Mean values for seven assays \pm standard deviations (SD) were calculated. Statistical analysis was performed using Student's $t$-test.

\section{RESULTS}

\section{The effect of glucose deprivation on the expression of ORP150}

Figure 1 shows the expression of ORP150 and its glycosylated form GRP170 in fibroblasts (Fig. 1A, B) and in MCF7 cells (Fig. 1C, D). It is apparent that the expression of these proteins depends on the presence of glucose in culture medium and changes during the incubation.

The expression of GRP170 in fibroblasts was observed in cultures incubated both in high-glucose and low-glucose DMEM, independently of incubation time

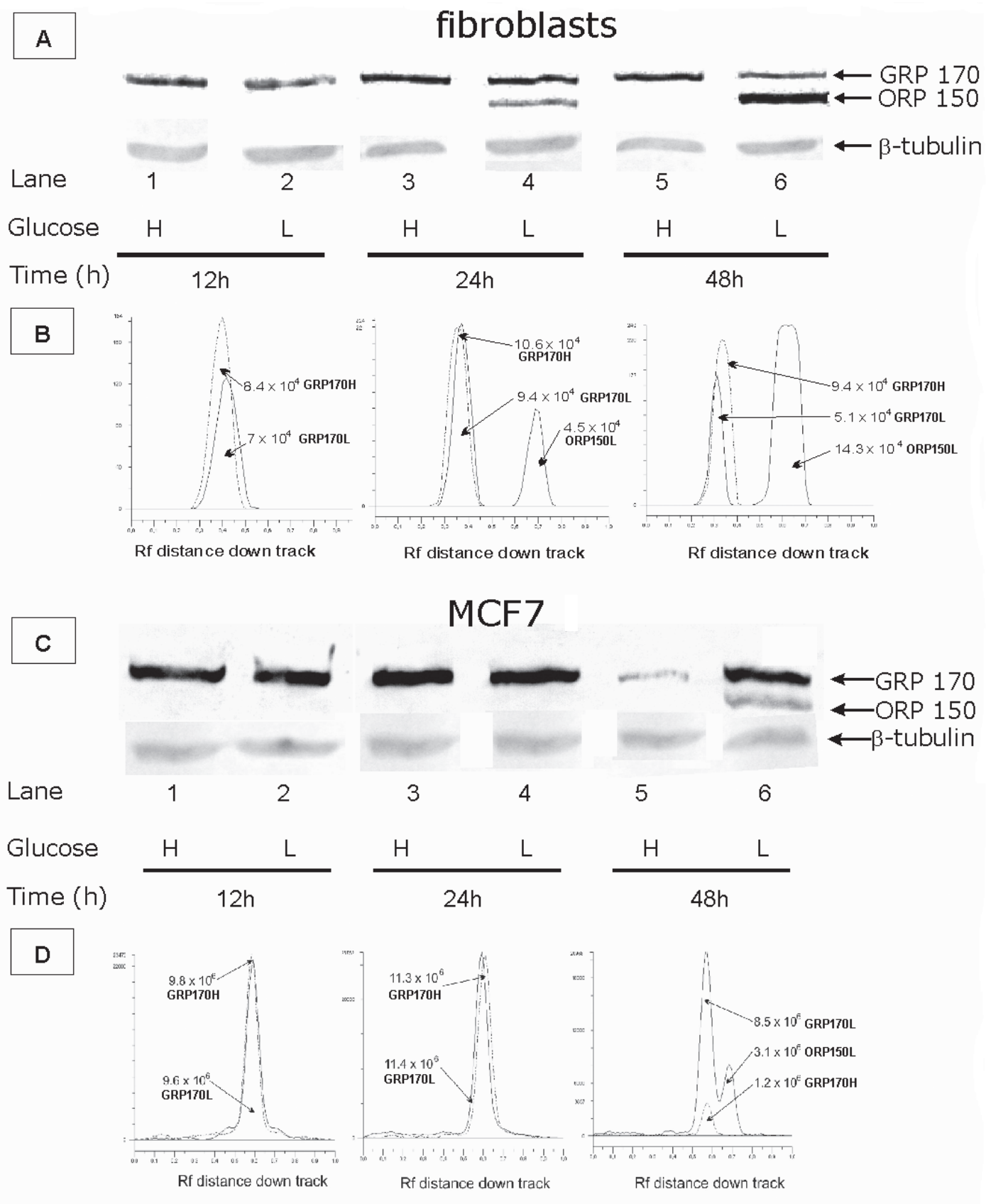

Figure 1. Western immunoblot analysis (A, C) and densitometric analysis (B, D) of GRP170/ORP150 synthesised by fibroblasts (A, B) and MCF7 cells (C, D).

Cells were grown in high-glucose $(\mathbf{H})$ or low-glucose (L) DMEM for 12 h, 24 h or 48 h. Samples containing $30 \mu g$ of protein were analyzed. 
A fibroblasts

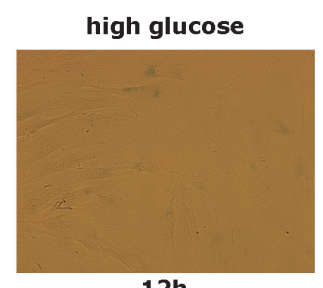

$12 \mathrm{~h}$

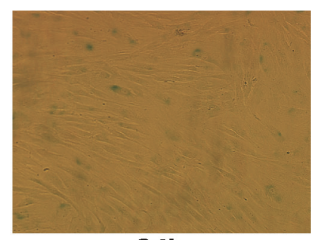

$24 h$

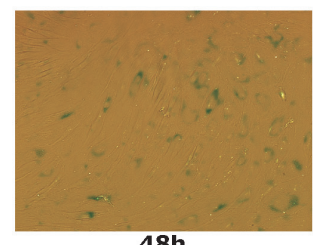

$48 h$

\section{B}

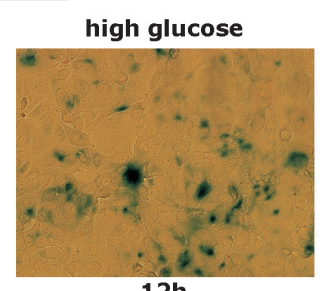

12h

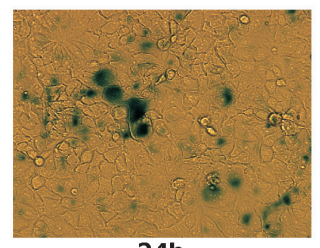

24h

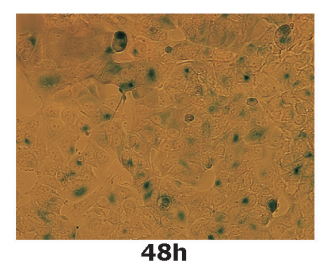

low glucose

12h

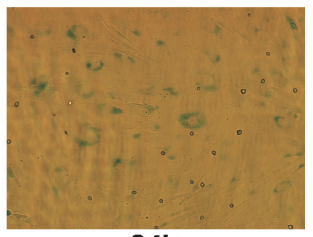

24h

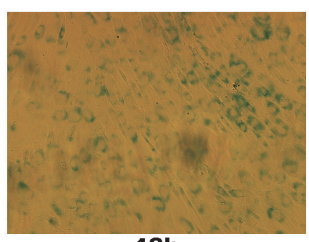

$48 h$

\section{MCF7}

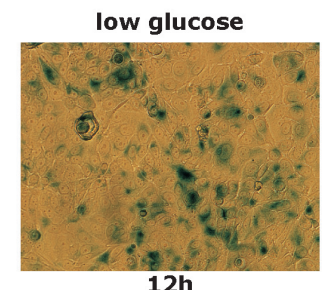

$12 \mathrm{~h}$

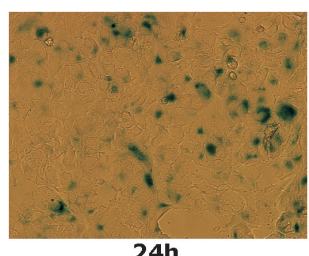

24h

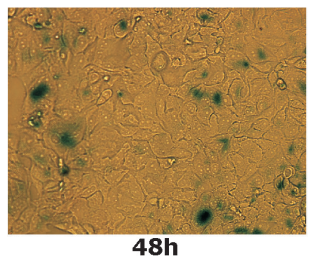

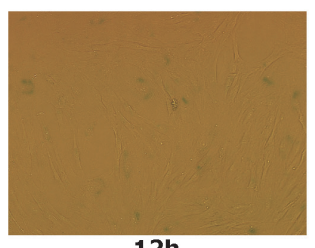

Figure 2. Cytochemical staining for SA- $\beta$-galactosidase in fibroblasts (A) and MCF7 cells (B).

Cells were cultured for $12 \mathrm{~h}, 24 \mathrm{~h}$ or $48 \mathrm{~h}$ in high- or low-glucose DMEM. SA- $\beta$-galactosidase cytochemical staining shown here is a representative photograph (magnification $100 \mathrm{x}$ ).

(Fig. 1A; lanes 1-6). It is of interest that fibroblasts incubated in high-glucose (Fig. 1A; lane 1) or low-glucose DMEM (lane 2) for $12 \mathrm{~h}$ did not express ORP150. Prolongation of incubation up to $24 \mathrm{~h}$ in low-glucose medium resulted in the appearance of ORP150 (Fig 1A; lane 4) and its increased amount during further incubation up to 48 h (Fig. 1A; lane 6). No such phenomenon was observed in high-glucose medium. Fibroblasts did not express ORP150 in this conditions. These observations were confirmed by densitometric analysis (Fig. 1B).

The expression of GRP170 in MCF7 cells was observed in cultures incubated both in high-glucose and low-glucose DMEM, independently of incubation time (Fig. 1C; lanes 1-6). The MCF7 cells incubated in high-glucose (Fig. 1C; lanes 1 and 3) or low-glucose DMEM (lanes 2 and 4 ) for $12 \mathrm{~h}$ or $24 \mathrm{~h}$ did not express ORP150. We observed strong expression of GRP170 only. Prolongation of incubation in high-glucose DMEM up to $48 \mathrm{~h}$ resulted in reduction of GRP170 expression (Fig. 1C; lane 5). Incubation for $48 \mathrm{~h}$ in low-glucose DMEM resulted in strong expression of ORP150 (Fig. $1 \mathrm{C}$; lane 6). These conclusions were confirmed by densitometric analysis (Fig. 1D).

\section{The effect of glucose deprivation on SA $\beta$-galactosidase expression}

The SA- $\beta$-galactosidase expression was determined with the use of chromogenic X-gal substrate. Normal dividing cells do not hydrolyse this substrate. However, cells with a division blockade become intensely blue stained due to SA- $\beta$-galactosidase expression. Figure 2 displays representative photographs of fibroblasts (Fig. 2A) and MCF7 cells (Fig. 2B) positive for SA- $\beta$ galactosidase staining. The SA- $\beta$-galactosidase activity was nearly constant in fibroblasts cultured for $12 \mathrm{~h}$ in low or high-glucose medium. In contrast, the MCF7 cells cultured for $12 \mathrm{~h}$ in low-glucose medium showed a higher SA- $\beta$-galactosidase expression in comparison to cells maintained in high-glucose medium. After 24 $\mathrm{h}$ of incubation no differences were observed between cultures incubated in high or low-glucose media for either cell line. The prolongation of incubation time up to $48 \mathrm{~h}$ in low-glucose medium caused contrasting changes of SA- $\beta$-galactosidase expression in the investigated cells. Whereas in fibroblasts it increased significantly, a deep decrease of this enzymes expression was observed in MCF7 cells (Fig. 2).

\section{The effect of glucose deprivation on acid $\beta-D$ - galactosidase activity}

We looked next for the effect of glucose deprivation on acid $\beta$-D-galactosidase activity. Figure 3 shows the $\beta$-D-galactosidase activity in fibroblasts and in MCF7 cells cultured in high- or low-glucose DMEM. After $12 \mathrm{~h}$ of culturing of fibroblasts in low-glucose DMEM a slight decrease of this enzymes activity was observed in comparison to the cells maintained in high-glucose medium. In contrast to fibroblasts, the activity of acid $\beta$-D-galactosidase in MCF7 cells incubated in low-glucose medium was significantly higher (Fig. 3B). After $24 \mathrm{~h}$ of culturing no differences between cultures incubated in high or low-glucose media were observed for either cell line. Further prolongation of incubation to $48 \mathrm{~h}$ resulted in a slight increase of acid $\beta$-D-galactosidase activity in fibroblasts, and a significant decrease in MCF7 cells (Fig. 3).

\section{The effect of glucose deprivation on apoptosis and necrosis}

Figure 4 shows the percentage of apoptotic and necrotic fibroblasts and MCF7 cells incubated in high- or low-glucose DMEM. No significant differences between cultures were observed regardless of cell type, medium, 

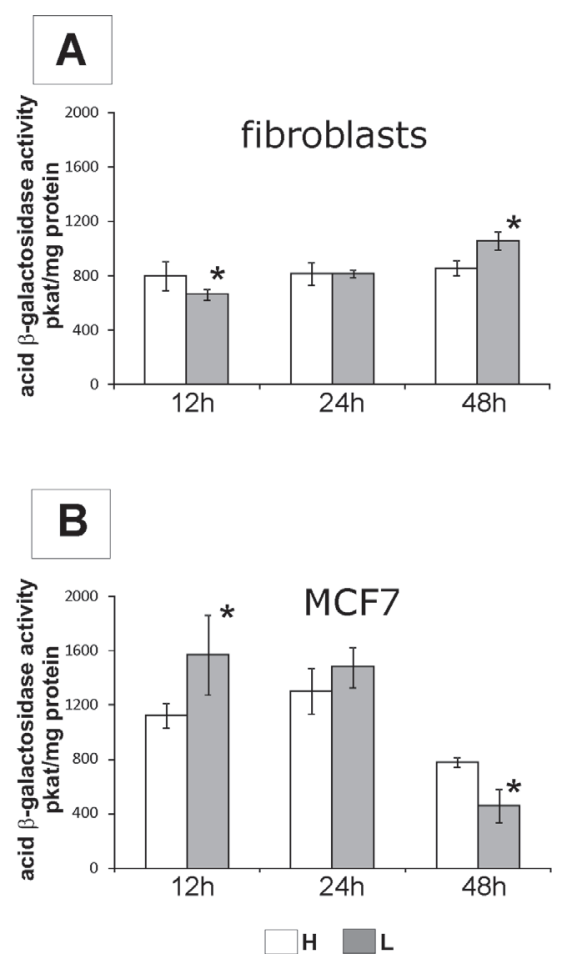

Figure 3. Effect of glucose deprivation on acid $\beta$-D-galactosidase activity in fibroblasts and breast cancer cells.

Cells were cultured for $12 \mathrm{~h}, 24 \mathrm{~h}$ or $48 \mathrm{~h}$ in high-glucose $(\mathrm{H})$ or low-glucose (L) DMEM. Enzyme activity in whole cell lysates is shown as pkat/mg of protein. Mean values from seven experiments \pm S.D. are presented. Statistical significance at ${ }^{*} p<0.05$.

or culture duration up to 24 hours (Fig. 4A, B). Further incubation to $48 \mathrm{~h}$ resulted in different effects in fibroblasts and MCF7 cells. In fibroblasts the apoptosis frequency did not change significantly in low- or high-

\section{fibroblasts}
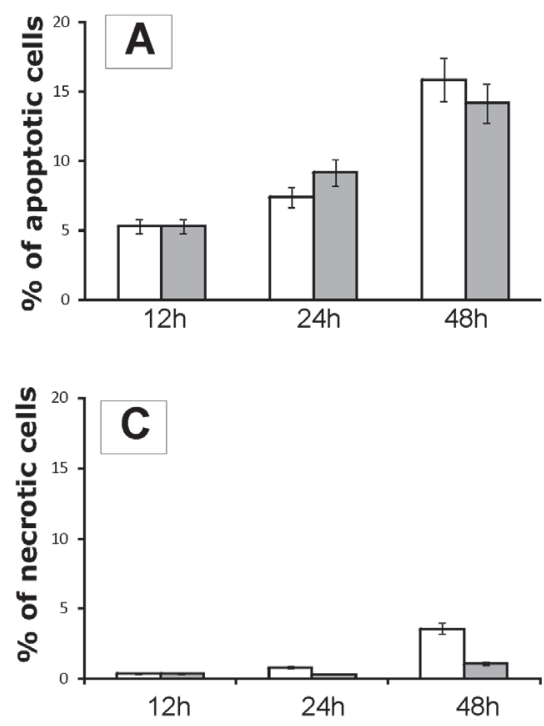

$\square \mathrm{H} \square \mathrm{L}$

Figure 4. Effect of glucose deprivation on apoptosis and necrosis in fibroblasts and MCF7 cells.

Cells (A, C - fibroblasts, B, D - MCF7) were cultured for $12 \mathrm{~h}, 24 \mathrm{~h}$ or $48 \mathrm{~h}$ in high-glucose $(\mathbf{H})$ or low-glucose (L) DMEM. Mean values from seven experiments \pm S.D. are presented. Statistical significance at ${ }^{*} p<0.05$.

glucose medium (Fig. 4A), whereas the MCF7 cells demonstrated $35 \%$ reduction of apoptosis in comparison to cells maintained in high-glucose medium. Those cultured in high-glucose medium showed no significant change compared to shortage culturing (Fig. 4B).

It is apparent from Fig. 4C that fibroblasts demonstrated a low tendency to undergo necrosis which, increased with the incubation time in low-glucose medium only. The MCF7 cells demonstrated significantly higher tendency to undergo necrosis in comparison to fibroblasts in either medium; the rate of necrosis roughly doubled in 48-hour cultures (Fig. 4D).

\section{DISCUSSION}

We have shown in this study that glucose deprivation evokes inducible overexpression of ORP150 in fibroblasts and in human breast carcinoma cells. In contrast to normal fibroblasts, this phenomenon was accompanied by inhibition of apoptosis and senescence of MCF7 cells incubated in low-glucose medium. We observed opposite changes in SA- $\beta$-galactosidase expression and in acid $\beta$-D-galactosidase activity in MCF7 cells in comparison to normal fibroblasts. Whereas in fibroblasts the expression and activity of these enzymes in low-glucose medium significantly increased in comparison with highglucose medium, a deep decrease of those parameters was observed in MCF7 cells. The breast cancer cells cultured in low-glucose medium for $48 \mathrm{~h}$ showed significantly lower expression of SA- $\beta$-galactosidase and reduced acid $\beta$-D-galactosidase activity in comparison with the same cells cultured in high-glucose medium.

We observed ORP150 induction in fibroblasts and in MCF7 cells incubated in low-glucose medium, in ER stress conditions. We suggest that inducible overexpression of ORP150 affects the expression of SA- $\beta$ galactosidase and the activity of acid $\beta$-galactosidase, biomarkers of cellular senescence. Increased chaperone syn-

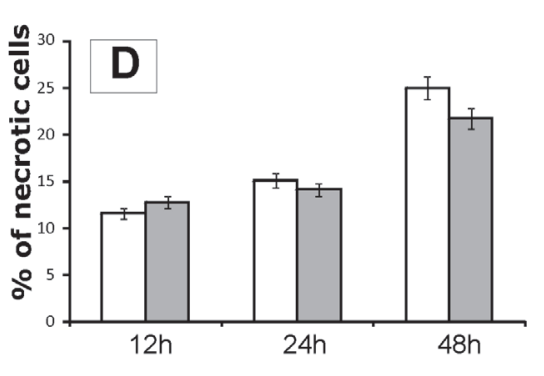

MCF7

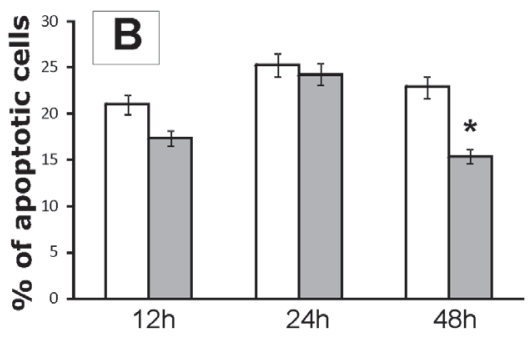
thesis has been shown to promote cancer cell proliferation and resistance to chemotherapeutic drugs. Thus, in most tumours such as breast, lung and prostate cancers, large accumulation of cytoprotective proteins has been detected. These proteins can be found inside the cell as well as in the extracellular matrix (ECM). Chaperones located in the ECM are able to either stimulate or suppress the immunological system (Sherman \& Multhoff, 2007).

What may be the specific physiological significance of the increased chaperone expression in cancers? Activation of certain oncogenes (e.g. RAS, HER-2 or PTEN mutation) in normal cells stimulates TP53 and forces cells to senescence, which serves as an important defense mechanism against cancer transformation. Depletion of various chaperones triggers senescence, suggesting that these proteins serve as endogenous suppressors of a latent senescence program. In other words, in many cancers vari- 
ous chaperones keep P53 under control, thus allowing cancer transformation to occur. The inhibition of P53 biosynthesis and functioning is one of the mechanisms protecting cancer cells against senescence. It is possible that tumours accumulate chaperones to avoid the oncogene-induced senescence. This mechanism of evading activation of the senescence program in tumours could be an alternative to acquiring mutations in the TP53 pathway, which takes place in many tumours (Sherman \& Multhoff, 2007).

In agreement with the cytoprotective role of molecular chaperones it has been shown that they can prevent stress-induced apoptotic death (Soti et al., 2003; Mosser \& Morimoto; 2004). Overexpression of Hsp70 chaperones (ORP150 belongs to this family) prevents cytochrome c release from mitochondria, blocks apoptosome formation by binding to the apoptotic protease-activating factor (Apaf-1), inhibits the release of apoptosis inducing factor (AIF) from mitochondria and prevents the loss of mitochondrial transmembrane potential. The AIF released from mitochondria binds to HSP70 and this interaction makes the nuclear import of AIF impossible (Mosser \& Morimoto; 2004).

Little is known about the functions of chaperones in non-dividing cells. Senescence is thought to play an important role in tumour suppression. Cellular senescence is more than just replicative senescence. It is a common program that is activated by normal cells in response to various types of stress. It has been named "stress-induced premature senescence" (SIPS) (Palaniyappan, 2009). This type of senescence can act as a tumour suppressor in order to prevent damaged cells from multiplying as well as result from therapeutic treatments (Saretzki, 2010). Tumour suppressors prevent cells from transforming into cancer by forming molecular barriers for genomic instability and infinite proliferation. They normally induce either apoptosis or a permanent cell cycle arrest - senescence. Unfortunately, the factors that determine whether a cell enters apoptosis or senescence remain unrecognized (Saretzki, 2010).

The senescence program seems to represent a major obstacle to cancer emergence. Indeed, limiting cell division seems to be a perfect way of preventing tumour growth (Parkinson et al., 2005). Another alternative to achieve the same goal is through activation of apoptosis. Mammalian cells appear to utilise both programs to counteract the action of major oncogenes. In fact, as counterintuitive as it sounds, overexpression of major oncogenes can either activate apoptosis, as seen with $M Y C$, or trigger senescence as seen with $\mathrm{R} A S$, HER-2, $P T E N, R A F$, and other oncogenes of the $R A S$ family (Mason et al., 2004; Chen et al., 2005). Many cancer cells still can undergo senescence (so-called premature senescence) in response to activation of oncogenes: $\mathrm{R} A S$ or HER-2, or to various DNA-damaging drugs, like doxorubicin (Chang et al., 1999a; Chang et al., 1999b; Roninson, 2003; Dimri, 2005; Collado, 2007; Palaniyappan, 2009). In fact, the major mechanism of action of many anti-cancer drugs seems to be activation of the premature senescence program (Lowe et al., 2004; Narita \& Lowe, 2004). These findings demonstrate that the senescence program remains functional even after cancer transformation. Premature senescence in cancer cells depends upon activation of the cell cycle inhibitor P21, while P16 seems to be involved only in senescence of normal cells (Saretzki, 2010).

Induction of chaperones in cancer cells can lead to cancer progression and may be a major cause of chemotherapeutics resistance. It is one of the mechanisms pro- tecting cancer cells against entering the apoptotic family. Hence, chaperone inhibition may be a promising tool to decrease cytoprotection and to initiate apoptosis of cancer cells (Saretzki, 2010). Senescence and apoptosis normally counteract tumour development and to proliferate cancer cells must therefore overcome these important tumour suppressor mechanisms. Senescence emerges as an important tumour suppressor mechanism in vivo. Understanding and application of cellular senescence for cancer therapy has recently become a field of extensive research.

Our results indicate that inducible overexpression of ORP150, in ER stress conditions, exerts inhibitory effect on apoptosis and senescence in human breast carcinoma cells but not in normal fibroblasts. We suggest that ORP150 induction in cancer cells can lead to cancer progression and may be a major cause of chemotherapeutics resistance. It may be one of the mechanisms protecting cancer cells against entering the apoptotic pathway.

\section{REFERENCES}

Chang BD, Broude EV, Dokmanovic M, Zhu H, Ruth A, Xuan Y, Kandel ES, Lausch E, Christov K, Roninson IB (1999a) A senescence-like phenotype distinguishes tumor cells that undergo terminal proliferation arrest after exposure to anticancer agents. Cancer Res 59: 3761-3767

Chang BD, Xuan Y, Broude EV, Zhu H, Schott B, Fang J, Roninson IB (1999b) Role of $\mathrm{p} 53$ and p21waf1/cip1 in senescence-like terminal proliferation arrest induced in human tumor cells by chemotherapeutic drugs. Oncogene 18: 4808-4818.

Chatterjee S, Velicer LF, Sweeley CC (1975) Glycosphingolipidglycosyl hydrolases and glycosidases of synchronized human KB cells. J Biol Chem 250: 4972-4979.

Chen Z, Trotman LC, Shaffer D, Lin HK, Dotan ZA, Niki M, Koutcher JA, Scher HI, Ludwig T, Gerald W, Cordon-Cardo C, Pandolfi PP (2005) Crucial role of p53-dependent cellular senescence in suppression of Pten-deficient tumorigenesis. Nature 436: 725-730.

Collado M, Blasco MA, Serrano M (2007) Cellular senescence in cancer and aging. Cell 130: 223-233.

Dimri GP (2005) What has senescence got to do with cancer? Cancer Cell 7: 505-512.

Flores-Diaz M, Higuita JC, Florin I, Okada T, Pollesello P, Bergman T, Thelestam M, Mori K, Alape-Giron A (2004) A cellular UDPglucose deficiency causes overexpression of glucose/oxygen-regulated proteins independent of the endoplasmic reticulum stress elements. J Biol Chem 279: 21724-21731.

Harding HP, Calfon M, Urano F, Novoa I, Ron D (2002) Transcriptional and translational control in the Mammalian unfolded protein response. Annu Rev Cell Dev Biol 18: 575-599.

Jolly C, Morimoto RI (2000) Role of the heat shock response and molecular chaperones in oncogenesis and cell death. J Natl Cancer Inst 92: $1564-1572$

Kaufman RJ, Scheuner D, Schroder M, Shen X, Lee K, Liu CY, Arnold SM (2002) The unfolded protein response in nutrient sensing and differentiation. Nat Rev Mol Cell Biol 3: 411-421.

Kurz DJ, Decary S, Hong Y, Erusalimsky JD (2000) Senescence-associated (beta)-galactosidase reflects an increase in lysosomal mass during replicative ageing of human endothelial cells. J Cell Sci 113: 3613-3622.

Laemmli UK (1970) Cleavage of structural proteins during the assembly of the head of bacteriophage T4. Nature 227: 680-685.

Lowe SW, Cepero E, Evan G (2004) Intrinsic tumour suppression. Nature 432: 307-315.

Lundberg AS, Hahn WC, Gupta P, Weinberg RA (2000) Genes involved in senescence and immortalization. Curr Opin Cell Biol 12: 705-709.

Ma Y, Hendershot LM (2001) The unfolding tale of the unfolded protein response. Cell 107: 827-830.

Mason DX, Jackson TJ, Lin AW (2004) Molecular signature of oncogenic ras-induced senescence. Oncogene 23: 9238-9246.

Matsushita K, Matsuyama T, Nishimura H, Takaoka T, Kuwabara K, Tsukamoto Y, Sugita M, Ogawa S (1998) Marked, sustained expression of a novel $150-\mathrm{kDa}$ oxygen-regulated stress protein, in severely ischemic mouse neurons. Mol Brain Res 60: 98-106.

Mosser DD, Morimoto RI (2004) Molecular chaperones and the stress of oncogenesis. Oncogene 23: 2907-2918.

Narita M, Lowe SW (2004). Executing cell senescence. Cell Cycle 3: $244-246$. 
Nishigaki T, Okada S (1998) [beta-Galactosidosis (acid beta-galactosidase deficiency: GM1 gangliosidosis, Morquio B disease)]. Ryoikibetsu Shokogun Shirizu 403-406.

Noppe G, Dekker P, de Koning-Treurniet C, Blom J, van Heemst D Dirks RW, Tanke HJ, Westendorp RG, Maier AB (2009) Rapid flow cytometric method for measuring senescence associated betagalactosidase activity in human fibroblasts. Cytometry A 75: 910-916.

Palaniyappan A (2009) Cyclophosphamide induces premature senescence in normal human fibroblasts by activating MAP kinases. Biogerontology 10: 677-682.

Parkinson EK, Munro J, Steeghs K (2005) Replicative senescence as a barrier to human cancer. Biochem Soc Trans 28: 226-233.

Roninson IB (2003) Tumor cell senescence in cancer treatment. Cancer Res 63: 2705-2715.

Saretzki G (2010) Cellular senescence in the development and treatment of cancer. Curr Pharm Des 16: 79-100.

Severino J, Allen RG, Balin S, Balin A, Cristofalo VJ (2000) Is beta-galactosidase staining a marker of senescence in vitro and in vivo? Exp Cell Res 257: 162-171.

Sherman M, Multhoff G (2007) Heat shock proteins in cancer. Ann N Y Acad Sci 1113: 192-201.
Smith PK, Krohn RI, Hermanson GT, Mallia AK, Gartner FH, Provenzano MD, Fujimoto EK, Goeke NM, Olson BJ, Klenk DC (1985) Measurement of protein using bicinchoninic acid. Anal Biochem 150: 76-85.

Soti C, Sreedhar AS, Csermely P (2003) Apoptosis, necrosis and cellular senescence: chaperone occupancy as a potential switch. Aging Cell 2: 39-45.

Tsukamoto Y, Kuwabara K, Hirota S, Ikeda J, Stern D, Yanagi H, Matsumoto M, Ogawa S, Kitamura Y (1996) 150-kD oxygen-regulated protein is expressed in human atherosclerotic plaques and allows mononuclear phagocytes to withstand cellular stress on exposure to hypoxia and modified low density lipoprotein. I Clin Invest 98: 1930-1941.

Tsukamoto Y, Kuwabara K, Hirota S, Kawano K, Yoshikawa K, Ozawa K, Kobayashi T, Yanagi H, Stern DM, Tohyama M, Kitamura Y, Ogawa S (1998) Expression of the 150-kd oxygen-regulated protein in human breast cancer. Lab Invest 78: 699-706.

Yi TN, Zhao HY, Zhang JS, Shan HY, Meng X, Zhang J (2009): Effect of aspirin on high-glucose-induced senescence of endothelial cells. Chin Med J 122: 3055-3061.

Yoshida H (2007) ER stress and diseases. Febs J 274: 630-658. 